\section{Improving postoperative pain management in subpectoral tissue expander implant reconstruction of the breast using an elastomeric pump}

\author{
A Chaudhry ${ }^{1}$, S Hallam ${ }^{2}$, A Chambers ${ }^{2}$, AK Sahu ${ }^{2}$, S Govindarajulu ${ }^{2}$, S Cawthorn ${ }^{2}$ \\ ${ }^{1}$ Great Western Hospitals NHS Foundation Trust, UK \\ ${ }^{2}$ North Bristol NHS Trust, UK
}

ABSTRACT

INTRODUCTION Postoperative pain after breast surgery is one of the major factors contributing to delay in mobilisation and prolonged hospital stay. A retrospective analysis was performed of patients undergoing skin sparing mastectomy and insertion of a subpectoral implant. The aim was to determine whether the use of an elastomeric local anaesthetic pump improved pain control and length of stay.

METHODS Twenty-five consecutive patients undergoing the above procedure were sited with an elastomeric local anaesthetic infusion pump intraoperatively, in addition to standard regular and pro re nata analgesia. The control group comprised 25 patients undergoing the same procedure in the same year who received standard analgesia alone. Visual analogue scale scores were recorded for the duration of inpatient stay, as was any further analgesic requirement.

RESULTS The median age was 51 years (range: 26-75 years) in the intervention group and 50 years (range: 28-70 years) in the control group. The mean visual analogue scale score was 0.28 (standard deviation [SD]: 0.61) at 24 hours for the intervention group and 1.84 (SD: 0.37) for the control group ( $p<0.0001$ ). The mean length of stay was 1.8 days (SD: 0.71 days) for the intervention group and 2.28 days (SD: 0.94 days) for the control group ( $p=0.15)$. There were no complications involving catheter placement, leakage or toxicity relating to use of the local anaesthetic.

CONCLUSIONS There was significantly reduced pain with the use of the local anaesthetic infusion pump. The elastomeric pump is a step towards enhanced patient recovery after breast surgery in the case of skin sparing mastectomy and subpectoral tissue expander reconstruction.

\section{KEYWORDS}

Breast neoplasms - Breast reconstruction - Pain

Accepted 11 January 2015

CORRESPONDENCE TO

Sally Hallam, E: sally84hallam@gmail.com

One of the most concerning outcomes of the fourth report from the National Mastectomy and Breast Reconstruction Audit was the higher than expected incidence of postoperative pain in reconstructive patients (ie $16.5 \%$ and $20.1 \%$ for immediate and delayed reconstruction respectively). ${ }^{1}$ Postoperative pain after breast surgery is one of the major factors contributing to delay in mobilisation and prolonged hospital stay. Furthermore, the use of opiates contributes to postoperative nausea and vomiting (PONV). ${ }^{2}$ There is a move to a 23-hour stay for breast cancer surgery ${ }^{2}$ and, certainly, hospital stay has become considerably shorter over the past few years. The current acute median stay for breast reconstruction is 2.8 days. Most commonly, delayed discharge is due to postoperative pain, PONV and anxiety. ${ }^{3}$

We present a retrospective analysis of our experience with a portable elastomeric infusion device, which significantly reduces postoperative pain.

\section{Methods}

This retrospective analysis was performed in all consecutive female breast cancer patients undergoing skin sparing mastectomy, with or without nipple preservation and insertion of a subpectoral tissue expander implant. Two consultant surgeons performed all procedures, both surgeons used the wound infusion catheter, and there was no significant difference in intervention and control group distribution between the two. Patients were divided retrospectively into an intervention group (those who received a local anaesthetic elastomeric wound infusion catheter intraoperatively according to surgeon and anaesthetist preference) and a control group. Both groups received regular analgesia comprising paracetamol and diclofenac or ibuprofen (when not contraindicated). Weak or strong opiates were available to both groups as needed, in addition to patient controlled analgesia 


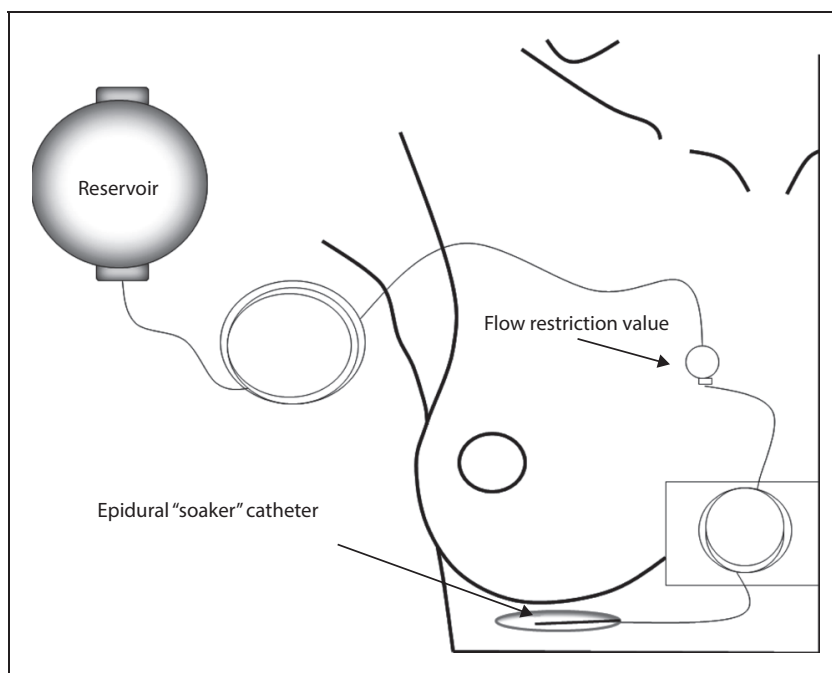

Figure 1 The elastomeric pump

(PCA) if prescribed by the anaesthetist. Informed verbal consent was obtained for participation in the analysis.

\section{Surgical technique}

The breast skin flap was infiltrated prior to skin incision, with $500 \mathrm{ml}$ of normal saline containing $1 \mathrm{ml}$ in $1,000 \mathrm{ml}$ of adrenaline, using an epidural needle injected into the subcutaneous plane. Sharp dissection was used as opposed to electrocautery. The subpectoral tissue expander was inserted and inflated with $200 \mathrm{ml}$ of normal saline.

On completion of the procedure, before skin closure, two $14 \mathrm{~F}$ drains were placed: one in the subpectoral pocket and the other under the mastectomy skin flap. Both were brought out inferior to the inframammary fold (IMF). In the intervention group, the elastomeric pump epidural catheter (Fig 1) was inserted under direct vision in the IMF and placed along it. This was then connected to the portable elastomeric infusion system (Easypump ${ }^{\circledR}$; B Braun, Melsungen, Germany). The device had a maximum capacity of $250 \mathrm{ml}$; when filled, it operated with sustained internal pressure. The pump was filled with $0.25 \%$ bupivacaine, delivered through a flow restrictor at a rate of $5 \mathrm{ml} / \mathrm{hr}$. The elastomeric infusion system differs from a syringe driver: it requires no intervention following insertion and disperses the preloaded volume of local anaesthetic automatically over 24 hours.

All patients were admitted electively for overnight stay and the catheter was removed prior to discharge by nursing staff on the ward. A modified visual analogue scale (VAS) was completed from time into the recovery room until discharge $(0=$ no pain, $1=$ mild pain, $2=$ moderate pain, 3 = severe pain). Medical records were scrutinised retrospectively for VAS score at 24 hours and length of stay.

\section{Statistical methods}

The chi-squared test was used and a $p$-value of $<0.05$ was considered to be statistically significant.

\section{Results}

Table 1 outlines the patient and tumour demographics for both the intervention and control groups. The median age was 53 years in the intervention group (range: $26-75$ years) and 52 years (range: $28-70$ years) in the control group.

In the intervention group, 21 patients underwent unilateral and four bilateral surgery. Twenty-four patients underwent sentinel node biopsy (SNB). Twenty of the SNB cases were for invasive carcinoma and four for multifocal ductal carcinoma in situ (DCIS). Five patients proceeded to axillary node clearance. In the control group, 19 patients underwent unilateral and six had bilateral surgery. Twenty patients underwent SNB. Seventeen of the SNB cases were for invasive carcinoma and three for multifocal DCIS. Four patients proceeded to axillary node clearance. When asked to rate their pain, patients were not asked to specify whether this pain was in the chest wall or the axilla. However, cases with axillary node clearance were distributed evenly between groups, (4 control, 5 intervention).

The mean VAS score was 0.28 (standard deviation [SD]: 0.61 ) at 24 hours for the intervention group and 1.84 (SD: $0.37)$ for the control group $(p<0.05)$. The mean length of stay was 1.8 days (SD: 0.71 ) for the intervention group and 2.28 days (SD: 0.94 days) for the control group $(p=0.15)$.

In the intervention group, there were no catheter dislodgements and all patients retained their pumps for the duration of their stay. There were no mechanical pump failures and all catheters were removed by nursing staff prior to discharge on the ward without complications. The nursing staff were happy to manage the pump on the ward and were enthusiastic about the device. Three patients required pro re nata opiate analgesia during their stay. One of these patients had a pre-existing opiate dependency. For the remaining 22 patients, paracetamol alone was sufficient.

In the control group, 23 patients required opiate analgesia: 11 were prescribed a pre-emptive syringe driver PCA intraoperatively, which was used by all 11 for 24 hours, 12 required additional pro re nata weak or strong opiates.

\section{Discussion}

The unexpectedly high rate of postoperative pain in breast reconstruction patients has called for clinicians to be more aware of postoperative analgesia regimes in improving the patient experience. ${ }^{1}$ In this analysis, the aim was to illustrate that with a simple and safe pump, pain control can be achieved to a satisfactory level, enhancing the patient experience and reducing the need for opiates in the immediate postoperative period.

Improving postoperative pain control and reducing the use of opiate analgesia is an important development given the trend towards 23-hour stay, day-case surgery and the enhanced recovery of breast surgery patients. ${ }^{2}$ Enhanced recovery after surgery (ERAS) is associated with a shortened hospital stay and minimal morbidity. ${ }^{4-7}$ A meta-analysis of surgically placed wound catheters (SPWCs) for the management of postoperative pain after breast surgery 
CHAUDHRY HALLAM CHAMBERS SAHU GOVINDARAJULU CAWTHORN
IMPROVING POSTOPERATIVE PAIN MANAGEMENT IN SUBPECTORAL TISSUE EXPANDER IMPLANT RECONSTRUCTION OF THE BREAST USING AN ELASTOMERIC PUMP

Table 1 Patient and tumour demographics for both the intervention and control groups

\begin{tabular}{|c|c|c|c|c|c|c|}
\hline Patient & Age & Disease status & Laterality & Sentinel node biopsy & VAS score at $24 \mathrm{hrs}$ & Length of stay \\
\hline \multicolumn{7}{|c|}{ Intervention group } \\
\hline 1 & 65 yrs & Prophylactic & Unilateral & No & 2 & 2 days \\
\hline 2 & 56 yrs & DCIS & Unilateral & Yes & 0 & 2 days \\
\hline 3 & 69 yrs & IDC & Unilateral & Yes & 1 & 3 days \\
\hline 4 & $35 \mathrm{yrs}$ & IDC & Unilateral & Yes & 0 & 2 days \\
\hline 5 & 28 yrs & IDC & Bilateral & Yes & 2 & 3 days \\
\hline 6 & 56 yrs & DCIS & Unilateral & Yes & 0 & 2 days \\
\hline 7 & $71 \mathrm{yrs}$ & IDC & Unilateral & Yes & 0 & 3 days \\
\hline 8 & 44 yrs & IDC & Bilateral & Yes & 1 & 2 days \\
\hline 9 & 75 yrs & DCIS & Unilateral & Yes & 0 & 3 days \\
\hline 10 & 34 yrs & IDC & Unilateral & Yes & 1 & 2 days \\
\hline 11 & 26 yrs & IDC & Unilateral & Yes & 0 & 2 days \\
\hline 12 & 48 yrs & IDC & Bilateral & Yes & 0 & 1 day \\
\hline 13 & 62 yrs & IDC & Unilateral & Yes & 0 & 1 day \\
\hline 14 & 51 yrs & IDC & Bilateral & Yes & 0 & 2 days \\
\hline 15 & 72 yrs & IDC & Unilateral & Yes & 0 & 1 day \\
\hline 16 & 52 yrs & IDC & Unilateral & Yes & 0 & 2 days \\
\hline 17 & 60 yrs & IDC & Unilateral & Yes & 0 & 1 day \\
\hline 18 & 69 yrs & IDC & Unilateral & Yes & 0 & 2 days \\
\hline 19 & 52 yrs & IDC & Unilateral & Yes & 0 & 2 days \\
\hline 20 & 44 yrs & DCIS & Unilateral & Yes & 0 & 1 day \\
\hline 21 & 45 yrs & IDC & Unilateral & Yes & 0 & 1 day \\
\hline 22 & 45 yrs & IDC & Unilateral & Yes & 0 & 2 days \\
\hline 23 & 47 yrs & IDC & Unilateral & Yes & 0 & 1 day \\
\hline 24 & 61 yrs & ILC & Unilateral & Yes & 0 & 1 day \\
\hline 25 & 48 yrs & IDC & Unilateral & Yes & 0 & 1 day \\
\hline \multicolumn{7}{|c|}{ Control group } \\
\hline 1 & 54 yrs & IDC & Unilateral & Yes & 2 & 3 days \\
\hline 2 & 50 yrs & IDC & Unilateral & Yes & 0 & 1 day \\
\hline 3 & 48 yrs & Prophylactic & Unilateral & No & 2 & 3 days \\
\hline 4 & 49 yrs & IDC & Unilateral & Yes & 0 & 1 day \\
\hline 5 & 60 yrs & IDC & Unilateral & Yes & 2 & 4 days \\
\hline 6 & 67 yrs & IDC & Unilateral & Yes & 2 & 2 days \\
\hline 7 & 53 yrs & Prophylactic & Bilateral & No & 1 & 2 days \\
\hline 8 & 65 yrs & IDC & Bilateral & Yes & 2 & 2 days \\
\hline 9 & 38 yrs & IDC & Unilateral & Yes & 2 & 3 days \\
\hline 10 & 61 yrs & IDC & Unilateral & Yes & 0 & 1 day \\
\hline 11 & 34 yrs & Prophylactic & Bilateral & No & 2 & 2 days \\
\hline 12 & 28 yrs & DCIS & Unilateral & Yes & 2 & 3 days \\
\hline 13 & 50 yrs & DCIS & Unilateral & Yes & 2 & 2 days \\
\hline 14 & 36 yrs & IDC & Unilateral & Yes & 2 & 2 days \\
\hline 15 & $46 \mathrm{yrs}$ & IDC & Unilateral & Yes & 2 & 2 days \\
\hline
\end{tabular}


CHAUDHRY HALLAM CHAMBERS SAHU GOVINDARAJULU CAWTHORN
IMPROVING POSTOPERATIVE PAIN MANAGEMENT IN SUBPECTORAL TISSUE EXPANDER IMPLANT RECONSTRUCTION OF THE BREAST USING AN ELASTOMERIC PUMP

\begin{tabular}{|c|c|c|c|c|c|c|}
\hline Patient & Age & Disease status & Laterality & Sentinel node biopsy & VAS score at $24 \mathrm{hrs}$ & Length of stay \\
\hline 16 & 38 yrs & IDC & Unilateral & Yes & 2 & 3 days \\
\hline 17 & 49 yrs & IDC & Unilateral & Yes & 2 & 2 days \\
\hline 18 & 62 yrs & ILC & Bilateral & Yes & 2 & 3 days \\
\hline 19 & 50 yrs & IDC & Unilateral & Yes & 2 & 3 days \\
\hline 20 & 52 yrs & IDC & Unilateral & Yes & 0 & 1 day \\
\hline 21 & 49 yrs & Prophylactic & Bilateral & No & 0 & 1 day \\
\hline 22 & 60 yrs & Prophylactic & Bilateral & No & 2 & 3 days \\
\hline 23 & 65 yrs & DCIS & Unilateral & Yes & 0 & 1 day \\
\hline 24 & 70 yrs & IDC & Unilateral & Yes & 2 & 4 days \\
\hline 25 & 64 yrs & IDC & Unilateral & Yes & 2 & 3 days \\
\hline
\end{tabular}

looked at 4 randomised controlled trials (RCTs) including a total of 147 women. ${ }^{8}$ This study showed a trend towards improved pain control. Although it was poorly powered, it was encouraging in terms of the safety and efficacy of SPWCs.

A 12-point protocol of enhanced recovery after breast surgery has been identified by Arsalani-Zadeh $e t a l{ }^{2}$ They encourage the use of thoracic blocks, from both analgesic and anaesthetic viewpoints. The elastomeric pump may also contribute to this protocol where the surgeon is able to perform the procedure without the need for an anaesthetist in performing such blocks.

The use of local anaesthesia in breast surgery was pioneered by William Stewart Halsted in 1882 . While the patient undergoing radical mastectomy had a prolonged hospital stay and recovery lasting several weeks, he and his colleagues made a breakthrough for the patient experience by the blockages of sensory nerves using cocaine hydrochlorate. ${ }^{9}$ The use of local anaesthetic pumps in aesthetic breast surgery has been described. A significant pain reduction was seen in patients undergoing breast reduction surgery as well as significantly reduced use of oral opioids and incidence of PONV with a bupivacaine pump used over $48-55$ hours. ${ }^{10}$ Furthermore, studies in subpectoral breast augmentation have proven the benefit of a sustained release of local anaesthetic with a sustained release lidocaine gel placed in the subpectoral pocket. ${ }^{11}$

In our study, the elastomeric pump is an element of this pathway that we feel can be achieved easily in hospitals and it represents a step towards tackling the high postoperative pain rates after breast reconstruction. The most critical time period for controlling postoperative pain is during the first 48 hours. ${ }^{12}$ The use of the pump has facilitated the pathway of care for shoulder surgery ${ }^{13,14}$ and had given promise for similar use in breast surgery. Following breast reconstruction after skin sparing mastectomy, it is common practice to infuse a local anaesthetic either into the drains or subcutaneously prior to skin incision. Local anaesthetics have proven benefit compared with placebo; however, there is little evidence to support the use of pre-emptive versus postincisional wound infiltration. ${ }^{15,16}$
Continuous infusion local anaesthetic pumps are a proven alternative method of postoperative pain control as demonstrated in two RCTs in breast surgery, relating to breast reduction and axillary lymph node dissection. ${ }^{10,17}$ Furthermore, in considering enhanced recovery in breast surgery, they certainly have been found to be helpful. ${ }^{18}$ For the pump to be effective, the catheter must be placed and anchored in the fascia of the wound, ${ }^{19}$ as demonstrated in abdominoplasty procedures. This is not difficult to achieve as the epidural catheter can be placed under direct vision in the IMF and left along the inside of the wound before being anchored to the skin with a suture.

\section{Conclusions}

The use of the local anaesthetic wound infusion catheter resulted in significantly reduced pain in our analysis and we intend to perform a RCT to prove its efficacy, both from a patient perspective and with regard to length of hospital stay. With proper surgical technique, catheter placement, and education of staff and patients, the elastomeric pump is a promising step towards enhanced patient recovery after breast surgery in the case of skin sparing mastectomy and subpectoral tissue expander reconstruction. In the future, this may be rolled out to encompass patients undergoing latissimus dorsi flap reconstruction and other types of reconstruction following breast cancer surgery.

\section{Declaration}

None of the authors have any financial interests in the Easypump ${ }^{\circledR}$.

\section{References}

1. National Mastectomy and Breast Reconstruction Audit 2011. Leeds: NHS Information Centre; 2011

2. Arsalani-Zadeh R, EIFadl D, Yassin N, MacFie J. Evidence-based review of enhancing postoperative recovery after breast surgery. Br J Surg 2011; 98 181-196.

3. Marla S, Stallard S. Systematic review of day surgery for breast cancer. Int $\mathrm{J}$ Surg 2009; 7: 318-323. 
CHAUDHRY HALLAM CHAMBERS SAHU GOVINDARAJULU CAWTHORN
IMPROVING POSTOPERATIVE PAIN MANAGEMENT IN SUBPECTORAL TISSUE EXPANDER IMPLANT RECONSTRUCTION OF THE BREAST USING AN ELASTOMERIC PUMP
4. Walter CJ, Collin J, Dumville JC et al. Enhanced recovery in colorectal resections: a systematic review and meta-analysis. Colorectal Dis 2009; 11 344-353.

5. Lemmens L, van Zelm R, Borel Rinkes I et al. Clinical and organizational content of clinical pathways for digestive surgery: a systematic review. Dig Surg 2009; 26: 91-99.

6. Barbieri A, Vanhaecht K, Van Herck $P$ et al. Effects of clinical pathways in joint replacement: a meta-analysis. BMC Med 2009; 7: 32

7. Dooley WC. Ambulatory mastectomy. Am J Surg 2002; 184: 545-548.

8. Raghavendra GK, Sreenivasa RH, Ashok K et al. Surgically placed wound catheters (SPWC) and local anaesthetic infusion in breast surgery: efficacy and safety analysis. Breast Dis 2011; 33: 1-8.

9. Halsted WS. Practical comments on the use and abuse of cocaine, suggested by its use in more than 1000 minor surgical operations. NY Med J 1885; 42: 294-295.

10. Rawlani V, Kryger ZB, Lu L, Fine NA. A local anaesthetic pump reduces postoperative pain and narcotic and antiemetic use in breast reconstruction surgery: a randomized controlled trial. Plast Reconstr Surg 2008; 122: 39-52.

11. Zhibo X, Miaobo Z. Effect of sustained-release lidocaine on reduction of pain after subpectoral breast augmentation. Aesthet Surg J 2009; 29: 32-34.

12. Tebbetts JB. Dual plane breast augmentation: optimizing implant-soft-tissue relationships in a wide range of breast types. Plast Reconstr Surg 2001; 107: $1,255-1,272$
13. Little K, Pillai A, Fazzi U, Storey N. Local anaesthetic infusion with elastomeric pump after arthroscopic subacromial decompression. Ann R Coll Surg Engl 2007; 89: 410-413.

14. Savoie F, Field LD, Jenkins RN et al. The pain control infusion pump for postoperative pain control in shoulder surgery. Arthroscopy 2000; 16 339-342.

15. Rica MA, Norlia A, Rohaizak M, Naqiyah I. Preemptive ropivacaine local anaesthetic infiltration versus postoperative ropivacaine wound infiltration in mastectomy: postoperative pain and drain outputs. Asian J Surg 2007; 30 34-39.

16. Johansson A, Kornfält J, Nordin $L$ et al. Wound infiltration with ropivacaine and fentanyl: effects on postoperative pain and PONV after breast surgery. J Clin Anesth 2003; 15: 113-118.

17. Schell SR. Patient outcomes after axillary lymph node dissection for breast cancer: use of postoperative continuous local anesthesia infusion. J Surg Res 2006; 134: 124-132.

18. Chavez-Abraham V, Barr JS, Zweibel PC. The efficacy of a lidocaine-infused pain pump for postoperative analgesia following elective augmentation mammaplasty or abdominoplasty. Aesthetic Plast Surg 2011; 35: 463-469. 